\title{
Anti-hepatic fibrosis effects of a novel turtle shell decoction by inhibiting hepatic stellate cell proliferation and blocking TGF- $\beta 1 /$ Smad signaling pathway in rats
}

\author{
GANPING BAI $^{1 *}$, GUOHE YAN ${ }^{2 *}$, GUOJIAN WANG ${ }^{1}$, PING WAN $^{1}$ and RONGHUA ZHANG ${ }^{1}$ \\ ${ }^{1}$ Department of Integrated Chinese and Western Medicine, Southwest Hospital; ${ }^{2}$ Institute of Combined Injuries, \\ The State Key Laboratory of Trauma, Burns and Combined Injury, College of Preventive Medicine, \\ The Third Military Medical University, Chongqing 400038, P.R. China
}

Received April 19, 2016; Accepted August 16, 2016

DOI: $10.3892 / o r .2016 .5078$

\begin{abstract}
Hepatic fibrosis (HF), a wound-healing response to a variety of chronic stimuli, is characterized by the excessive synthesis of extracellular matrix (ECM) proteins by hepatic stellate cells (HSC) and eventually the development of hepatic cirrhosis. Turtle shell pill (TSP) is a common traditional Chinese medicine used for preventing and treating $\mathrm{HF}$ and early hepatic cirrhosis, but its side-effects and the shortage of ingredients limit its clinical application. In addition, its mechanism of action is not clear. In the present study, we first improved the original formula of TSP to produce a novel turtle shell decoction (NTSD) with less toxicity and easier accessible materials. In a carbon tetrachloride $\left(\mathrm{CCl}_{4}\right)$-induced HF rat model, we observed that NTSD and TSP had similar effects on the improvement of liver functions in rats, including a decrease in serum alanine amino transferase (ALT) and aspartate amino transferase (AST) serum concentrations and increased albumin content in addition to a marked attenuation of $\mathrm{CCl}_{4}$-induced liver damage and fibrosis. NTSD containing rat serum inhibited rat liver stellate cell line HSC-T6 cell proliferation and induced cell apoptosis in vitro. Moreover, the NTSD treatment significantly decreased the transforming growth factor beta 1 (TGF- $\beta 1$ ) and Smad3 gene expression and increased inhibitory Smad7 gene expression in liver tissues of HF rats, suggesting that NTSD inhibited the ECM expression of HSC by downregulating the TGF- $\beta 1 / \mathrm{Smad}$ signaling pathway. The results of our rat model study revealed that
\end{abstract}

Correspondence to: Professor Ronghua Zhang, Department of Integrated Chinese and Western Medicine, Southwest Hospital, The Third Military Medical University, 29 Gaotanyan Avenue, Shapingba, Chongqing 400038, P.R. China

E-mail: zhrhlggg@163.com

${ }^{*}$ Contributed equally

Key words: hepatic fibrosis, a novel turtle shell decoction, TGF- $\beta 1$, Smad3, Smad7
NTSD showed good in vitro and in vivo anti-HF effects via proliferation inhibition and the induction of apoptosis of HSCs and blocked the TGF- $\beta 1 /$ Smad signaling pathway.

\section{Introduction}

Hepatic fibrosis (HF) refers to the abnormal proliferation of connective tissue in the liver, which is caused by the long-term existence of various liver injury factors (including alcohol and viruses). As the pathological characteristics of chronic liver disease, HF severely damages the morphology and function of normal liver tissue, and is an important link in the further development of various chronic liver diseases to full hepatic cirrhosis. It has been reported that hepatic cirrhosis resulted in 1.2 million deaths in 2013, up from 0.8 million deaths in 1990 (1). The essence of HF is the imbalance between synthesis and degradation of liver tissue ECM (2-4). After stimulation of various liver injury factors, the activated HSCs become responsive to both proliferative and fibrogenic cytokines (3). The role of TGF- $\beta 1$ in the HF pathological mechanism has been extensively studied, and it is considered to be the most central cytokine inducing HF $(5,6)$. HSCs react to TGF- $\beta 1$ exposure with a negative feedback regulation through the induction of Smad7. However, during chronic exposure to TGF- $\beta 1$ an epithelial-mesenchymal transition of HSCs into proliferative myofibroblast cells (MFBs) takes place (7). These cells are activated via autocrine TGF- $\beta$ signaling and develop an intrinsic Smad activation without Smad7 inhibition (8), leading to copious ECM secretion $(6,9)$.

TSP is a traditional Chinese medicine (TSM) formula for the treatment of chronic liver disease, which is from 'Golden Chamber' written long ago by the Eastern Han Dynasty physician Zhang Zhongjing. It is composed of turtle shell glue, gelatin, honeycomb, saltpeter and another 23 types of medicinal compounds. At present, TSP has been approved by the Chinese State Food and Drug Administration for the clinical prevention and treatment of HF and early hepatic cirrhosis, also confirming that it has obvious anti-fibrosis effects $(10,11)$. Moreover, in the TSP formula, turtle shell, Eupolyphaga sinensis and peach kernel were shown to inhibit the proliferation of connective tissue, but the specific mechanism of 


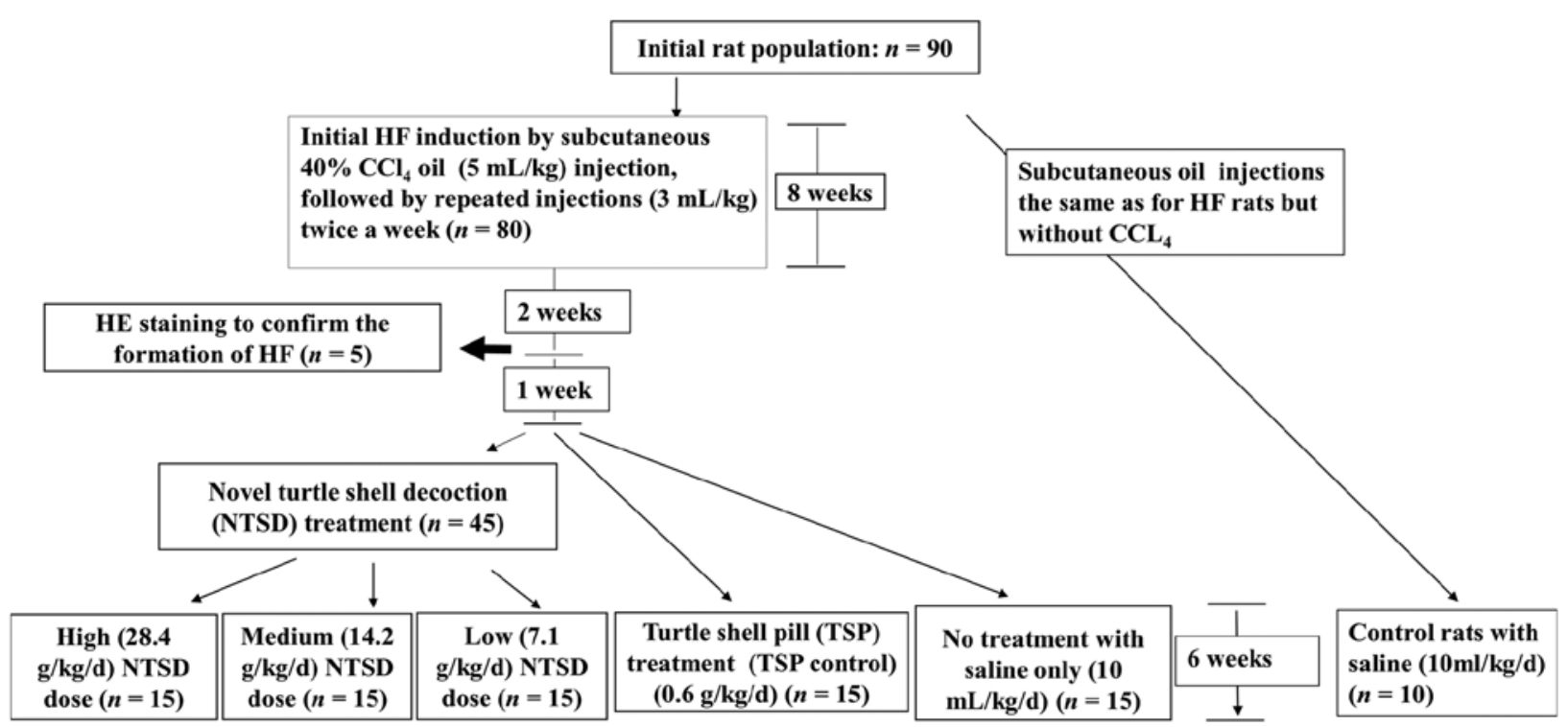

Figure 1. Flow chart of the present study.

action has not been studied in depth (12-14). TSP has serious side-effects that include mental fatigue and weight loss (15). In addition, some ingredients in the prescription, such as placenta hominis and Cordyceps are scarce resources and therefore expensive. These issues seriously limit its clinical application. In the present study, we modified the original formula of TSP to produce NTSD that has significantly less toxicity and gives easier access to the materials. The outcome rates of both formulas were compared in an HF rat model. It is suggested that blockade of the TGF- $\beta 1 / \mathrm{Smad}$ signaling pathway might be the mechanism underlying the effectiveness of TCM medication.

\section{Materials and methods}

Preparation of traditional Chinese medicine. Compound turtle shell softening liver pills (TSP) (batch number: 20090107) were bought from the Inner Mongolia Fu Rui Medicine Company, dissolved in distilled water to produce a solvent containing $0.06 \mathrm{~g} / \mathrm{ml}$ of crude drug. The materials to prepare NTSD included ground beetle, turtle shell, bupleurum root, Scutellaria root, Pinellia, Artemisia capillaris, cassia twig, peach kernel, Poria, Radix Astragali and white peony root (Chongqing Tongjunge Pharmacy, Chongqing, China). The above materials were soaked in distilled water for $1 \mathrm{~h}$, decocted (turtle shell, ground beetle first), filtered and concentrated, to make the decoction. The different crude drug dosages of NTSD in distilled water for application were 2.84, 1.42 and $0.71 \mathrm{~g} / \mathrm{ml}$, respectively. All the above preparation work was completed in the Department of Pharmacy, Chongqing Southwest Hospital, China.

Animals and cell cultures. Healthy male specific pathogen free Sprague-Dawley (SPF SD rats) were purchased from the Experimental Animal Center of Daping Hospital, Affiliated to the Third Military Medical University (Chongqing, China) and were fed in the SPF animal laboratory at temperatures between 18 and $22^{\circ} \mathrm{C}$ and a relative humidity of $50-80 \%$, with free access to a standard diet and sterile water. HSC-T6 cells were cultured in $5 \% \mathrm{CO}_{2}$ saturated humidity environment at $37^{\circ} \mathrm{C}$ using DMEM culture medium (containing $10 \% \mathrm{FBS}$, $100 \mathrm{U} / \mathrm{ml}$ penicillin and $100 \mathrm{U} / \mathrm{ml}$ streptomycin). The present study was approved by the Institutional Review Board of Southwest Hospital, the Third Military Medical University, and the methods were carried out in accordance with the approved guidelines.

$\mathrm{CCl}_{4}$-induced $\mathrm{HF}$ rat model and treatment. From an initial 90 rats, in 80 rats $\mathrm{HF}$ was induced by $\mathrm{CCl}_{4}$ (Chengdu Kelong Chemical Factory, Chengdu, Sichuan, China) mixed with olive oil (Sichuan Tianyuan Olive Oil Co., Sichuan, China) to a final $\mathrm{CCl}_{4}$ concentration of $40 \%$. The solution was injected as $5 \mathrm{ml} / \mathrm{kg}$ subcutaneously into the right hind leg, followed by repeated injections $(3 \mathrm{ml} / \mathrm{kg})$, twice a week for 8 weeks. Two weeks later, we randomly selected $5 \mathrm{HF}$ rats for $\mathrm{H} \& \mathrm{E}$ staining of liver tissue in order to confirm the formation of HF. The remaining 75 rats were 1 week later randomly divided into groups treated with low $(7.1 \mathrm{~g} / \mathrm{kg} /$ day $)$, medium $(14.2 \mathrm{~g} / \mathrm{kg} /$ day $)$ and high $(28.4 \mathrm{~g} / \mathrm{kg} /$ day) doses of NTSD as well as TSP $(0.6 \mathrm{~g} / \mathrm{kg} / \mathrm{day}, \mathrm{TSP}$ control) and normal saline $(10 \mathrm{ml} / \mathrm{kg} / \mathrm{day}$, as the no treatment control) by gavage for 6 weeks. The 10 control rats were treated the same way as the HF rats except that they received only olive oil and saline (Fig. 1).

Evaluation of hepatic fibrosis. After 6 weeks of treatment, rats in each group were fasted for $24 \mathrm{~h}$ and then anesthetized with a $3 \%$ sodium pentobarbital $(1 \mathrm{ml} / \mathrm{kg})$ by a single intraperitoneal injection. The same part of the right liver lobe was dissected from each rat for fixation in $100 \mathrm{ml} / 1$ formaldehyde solution and hematoxylin and eosin (H\&E) staining. The liver cell degeneration, collagen fiber hyperplasia and tissue morphology changes were investigated with the aid of a light microscope (BX51; Olympus, Tokyo, Japan). Quantitative and semi-quantitative methods were adopted to score the HFs. Zero points indicated no pathological changes in liver cells, a normal liver or no obvious collagen fiber hyperplasia; 1 point 
indicated that the proportion of degenerated liver cells were $<25 \%$ of the total cells, collagen fiber showed slight hyperplasia, central vein and portal area exhibited a small amount of fiber elongation but no septum formation; 2 points indicated that the proportion of degenerated liver cells was between 25 and $50 \%$ of all liver cells with obvious collagen fiber hyperplasia; the connective tissue around the central vein and portal area were thickened, which extended fiber chords to form incomplete fiber septa; 3 points indicated that the proportion of degenerated liver cells was between 50 and $75 \%$ of all liver cells with massive collagen fiber hyperplasia as well as false lobules, which were formed by individual complete or incomplete thick fiber septa; 4 points indicated that the proportion of degenerated liver cells was $>75 \%$ with thicker complete fiber septa and a large formation of false lobules.

Biochemical examination of liver functions. After 6 weeks of treatment, rats in each group that had been fasted for $24 \mathrm{~h}$ were given $3 \%$ sodium pentobarbital anesthesia $(1 \mathrm{ml} / \mathrm{kg})$ and blood samples collected from the femoral artery and subsequently the serum was isolated. The AU2700 full automatic biochemical instrument (Olympus) was used for the detection of serum ALT, AST, albumin and globulin content.

Preparation of drug-containing rat blood serum. Thirty healthy SPF SD rats were randomly divided into 6 groups ( 5 rats in each group), which were administered by gavage low ( $7.1 \mathrm{~g} / \mathrm{kg} /$ day $)$, medium $(14.2 \mathrm{~g} / \mathrm{kg} /$ day $)$ or a high $(28.4 \mathrm{~g} / \mathrm{kg} /$ day $)$ NTSD dose as well as TSP $(0.6 \mathrm{~g} / \mathrm{kg} / \mathrm{day})$ and normal saline as the control. All types of gastric perfusion medicine and liquids were delivered at a rate of $10 \mathrm{ml} / \mathrm{kg} /$ day. Gastric perfusion was performed twice a day for 3 consecutive days, with the rats having been fasted for $12 \mathrm{~h}$ before each perfusion. Two hours after the last gastric perfusion, Lumianning II (Jilin Huamu Animal Health Product, Co., Ltd., Changchun, Jilin, China) was injected intramuscularly for anesthesia and blood samples collected from the inferior vena cava. These samples were stored at $4^{\circ} \mathrm{C}$ overnight, then centrifuged for $15 \mathrm{~min}$ at $1000 \mathrm{x} \mathrm{g}$ to isolate the serum. The sera from the same groups were mixed, filtered through a $0.22-\mu \mathrm{m}$ filter then inactivated at $56^{\circ} \mathrm{C}$ for $30 \mathrm{~min}$, in order to remove possible biologically active substances, and samples stored at $-70^{\circ} \mathrm{C}$ until required for subsequent analysis.

Cell proliferation assay. HSC-T6 cells were seeded onto 96-well plates (the volume of each well was $150 \mu \mathrm{l}$ and contained $3 \times 10^{3}$ cells), and the culture medium (containing $20 \%$ of different doses of NTSD containing serum) was changed after $24 \mathrm{~h}$, with equivalent volume TSP-containing serum treated cells as the positive control, an equivalent volume of normal rat serum-treated cells as the normal control, and saline-treated HF cells as the negative control. The 96-well plates $24,48,72$ and $96 \mathrm{~h}$, respectively, after incubation started were removed and the cell growth status observed using an inverted microscope (IX71; Olympus) and digital images were taken for a permanent record. Subsequently, we replaced each well with fresh medium, added $10 \mu$ l CCK-8 kit solution and removed the plates after 2.5 -h incubation, slightly oscillated them for $25 \mathrm{sec}$ to mix well, and then detected the light density at $450 \mathrm{~nm}$ using a plate reader (Victor X2 Multilabel plate reader; Perkin-Elmer, Waltham, MA, USA). The cell proliferation curve was plotted with the light density value as the $y$-axis and the processing time as the $\mathrm{x}$-axis. Each experiment was repeated 3 times.

Detection of cell cycle and apoptosis. HSC-T6 cells with $1 \times 10^{6} / \mathrm{ml}$ density were routinely cultured for $24 \mathrm{~h}$, and replaced by fresh medium (containing $20 \%$ of different doses of normal serum, NTSD or TSP medicated serum). After $72 \mathrm{~h}$, cells from each group were collected and the cell number counted to ensure each group contained cell numbers from $1 \times 10^{4}-2 \times 10^{6}$. Twenty-four to $72 \mathrm{~h}$ after $80 \%$ ethanol fixation, cells were stained with propidium iodide (PI, $4 \mathrm{mg} / \mathrm{ml}$; Sigma-Aldrich), and flow cytometry (BD FACSCalibur; BD Biosciences, Franklin Lakes, NJ, USA) used to detect and analyze cell cycle changes. Each experiment was repeated 3 times.

For the detection of cell apoptosis, we took $100 \mu \mathrm{l}$ cell suspensions (5-10 million cells), added $195 \mu \mathrm{l}$ binding buffer to re-suspend the cells and mixed them thoroughly with $5 \mu \mathrm{l}$ Annexin V-FITC (Beyotime Institute of Biotechnology, Beijing, China). Then the samples were incubated for $10 \mathrm{~min}$ in the dark at room temperature $\left(20-25^{\circ} \mathrm{C}\right)$, centrifuged for $5 \mathrm{~min}$ at $1000 \mathrm{x}$ g, re-suspended in $195 \mu \mathrm{l}$ binding buffer, mixed with $10 \mu \mathrm{PI}$, and cell apoptosis was detected by flow cytometry. Each experiment was repeated 3 times.

Immunohistochemistry. The $4 \mu \mathrm{m}$ paraffin or $6 \mu \mathrm{m}$ frozen sections from liver tissue of rats in all groups were immunostained with anti-TGF- $\beta 1$ antibody (1:400; Santa Cruz Biotechnology, Inc., Santa Cruz, CA, USA), anti-Smad3 antibody (1:400; Santa Cruz Biotechnology) and anti-Smad7 antibody (1:400; Santa Cruz Biotechnology) and detection kit (ZSGB-BIO, Beijing, China) reagents. Pepsin (ZSGB-BIO) digestion was used for antigen retrieval and a $\mathrm{DAB}$ color reagent kit (ZSGB-BIO) was used to develop the color. Under the microscope, 5 non-overlapping fields in each section were selected under a high power field $(x 400)$. Image-Pro Plus software (Media Cybernetics, Bethesda, MD, USA) was used to analyze the mean optical density value.

Western blot analysis. Total protein was extracted by western and IP cell lysis solution (Beyotime Institute of Biotechnology, Shanghai, China) according to the manufacturer's instructions from liver tissues of rats in all groups, and the protein concentration measured with a BCA protein concentration kit (Beyotime Institute of Biotechnology). The primary antibodies included anti-TGF- $\beta 1$ antibody (1:100; Santa Cruz Biotechnology), anti-Smad3 antibody (1:200; Santa Cruz Biotechnology), anti-Smad7 antibody (1:200; Santa Cruz Biotechnology) as well as proliferating cell nuclear antigen (PCNA) antibody (1:800; Millipore, Billerica, MA, USA).

RT-PCR. Both liver tissue and HSC-T6 cell samples were extracted with TRIzol reagent (Invitrogen, Carlsbad, CA, USA) to obtain their total RNA, according to the manufacturer's instructions. Then, we used a PCR kit (Takara, Dalian, China) with the total RNA as a template to amplify the cDNA of TGF- $\beta 1$, Smad3, Smad7 and PCNA genes, and with $\beta$-actin gene added as the internal reference. Reverse transcription reaction conditions were: $30^{\circ} \mathrm{C}$ for $10 \mathrm{~min} ; 42^{\circ} \mathrm{C}$ for $30 \mathrm{~min}$, 
Table I. The sequences of RT-PCR primers of TGF- $\beta 1$, Smad3, Smad7, PCNA and $\beta$-actin genes.

\begin{tabular}{lll}
\hline Gene & \multicolumn{1}{c}{ Forward (5'-3') } & Reverse (5'-3') \\
\hline PCNA & CCTGCTGGGACATCAGTTCG & GGAGACAGTGGAGTGGCTTT \\
TGF- $\beta 1$ & CCGCAACAACGCAATCTATG & AGCCCTGTATTCCGTCTCCTT \\
Smad3 & GACTAGGTGTGAGCCCTTTAC & ATGGTTGACCCACATCCTGGTG \\
Smad7 & TTTACAACCGCAGCAGTTAC & AAGATGACCTCCAGCCAGC \\
-actin & CCGTGAAAAGATGACCCAGAT & CATTGCCGATAGTGATGACCT \\
\hline
\end{tabular}

Table II. NTSD improves the liver function of $\mathrm{CCl}_{4}$ induced HF rats.

\begin{tabular}{lcccccc}
\hline Rats & Treatment (g/kg/day) & $\mathrm{N}$ & ALT (IU/l) & AST (IU/l) & Globulin (g/l) & Albumin (g/l) \\
\hline Control & Saline & 10 & $36.72 \pm 7.63$ & $36.53 \pm 6.79$ & $33.85 \pm 1.85$ & $42.68 \pm 4.42$ \\
& Saline & 15 & $611.21 \pm 37.27^{\mathrm{a}}$ & $462.14 \pm 28.05^{\mathrm{a}}$ & $33.90 \pm 4.75$ & $27.05 \pm 4.81^{\mathrm{a}}$ \\
& NTSD & & & & $37.05 \pm 3.75$ & $37.85 \pm 3.08^{\mathrm{b}}$ \\
& 28.4 & 15 & $186.62 \pm 23.82^{\mathrm{b}, \mathrm{c}}$ & $156.57 \pm 24.98^{\mathrm{b}, \mathrm{c}}$ & $33.25 \pm 1.90^{\mathrm{b}}$ \\
HF & 14.2 & 15 & $174.73 \pm 39.52^{\mathrm{b}, \mathrm{c}}$ & $136.93 \pm 14.08^{\mathrm{b}, \mathrm{c}}$ & $30.45 \pm 3.22^{\mathrm{b}}$ & $38.21 \pm 5.92$ \\
& 7.1 & 15 & $153.82 \pm 18.44^{\mathrm{b}, \mathrm{c}}$ & $167.80 \pm 18.62^{\mathrm{b}}$ & $38.13 \pm 1.50^{\mathrm{b}}$ \\
& TSP & & & & $31.30 \pm 4.61$ \\
& 0.6 & 15 & $130.82 \pm 18.10^{\mathrm{b}}$ & $180.30 \pm 21.65^{\mathrm{b}}$ & $38.09 \pm 3.27^{\mathrm{b}}$ \\
\hline
\end{tabular}

${ }^{\mathrm{a}} \mathrm{P}<0.05$ vs. control; ${ }^{\mathrm{b}} \mathrm{P}<0.05$ vs. $\mathrm{HF}+$ saline; ${ }^{\mathrm{c}} \mathrm{P}<0.05$ vs. HF+TSP. ALT, alanine amino transferase; AST, aspartate amino transferase.

$99^{\circ} \mathrm{C}$ for $5 \mathrm{~min}, 5^{\circ} \mathrm{C}$ for $5 \mathrm{~min}, 1$ cycle. $\mathrm{PCR}$ reaction conditions: $94^{\circ} \mathrm{C}$ for $1 \mathrm{~min} ; 94^{\circ} \mathrm{C}$ for $30 \mathrm{sec}, 62.8^{\circ} \mathrm{C}$ for $30 \mathrm{sec}, 72^{\circ} \mathrm{C}$ for $1 \mathrm{~min}, 35$ cycles; $72^{\circ} \mathrm{C}$ extension for $5 \mathrm{~min}$. After the reaction, the PCR reaction product was ran on a $1 \%$ agarose gel electrophoresis and Goldview ${ }^{\mathrm{TM}}$ (G8140; Beijing SBS Genetech, Co., Ltd., Beijing, China) nucleic acid dye staining used to confirm the product. The sequences of primers of PCNA, TGF- $\beta 1$, Smad3 and Smad7 are shown in Table I.

Statistical analysis. For statistical analyses SPSS for Windows (version 13.0; SPSS, Inc., Chicago, IL, USA) was used and data shown as the mean $\pm \mathrm{SD}$. Student's t-test was used for comparison between groups with a normal distribution. $\mathrm{P}<0.05$ was considered to be a statistically significant difference.

\section{Results}

Preparation of NTSD. We first added and omitted several traditional Chinese medicines from the original TSP formula to prepare NTSD. The TSP formula contains 8 kinds of traditional Chinese medicines for resolving hard masses and recovering blood stasis, which have been maintained in the NTSD compounds, whereas 15 kinds of herbs inducing loss of vital Qi and pathogenic stagnation factors were omitted. Instead we added Radix Astragali, Poria, as well as Artemisia capillaris to the novel NTSD composition.

Hence, the complete formula of NTSD was as follows (in $142 \mathrm{~g}$ ): ground beetle $10 \mathrm{~g}$, turtle shell $15 \mathrm{~g}$, bupleurum root $10 \mathrm{~g}$, scutellaria root $12 \mathrm{~g}$, pinellia $15 \mathrm{~g}$, Artemisia capillaris 15 g, cassia twig 10 g, peach kernel 10 g, Poria 15 g, Radix Astragali $15 \mathrm{~g}$ and white peony root $15 \mathrm{~g}$. The ingredients were treated with soaking, decocting, filtering and concentration to derive the final NTSD formula.

NTSD improved HF-related biochemical liver indices induced by $\mathrm{CCl}_{4}$. As shown in Table II, compared with healthy control rats, the ALT and AST serum concentrations in the non-treated HF rats were significantly increased $(\mathrm{P}<0.05)$ and albumin concentrations significantly decreased $(\mathrm{P}<0.05)$ compared to the healthy control rats, which indicated that the liver function of HF rats was affected. However, TSP treatment significantly reduced the levels of ALT and AST levels increased in HF rats together with an increased albumin content, which proved its anti-HF effect. More importantly, NTSD also showed a significant improvement in liver function regarding ALT, AST and albumin serum concentrations, which supported its equal anti-HF efficacy. There was no significant difference between the effects of high, medium and low doses of NTSD on liver function suggesting that the effect of NTSD in low dose (7.1 $\mathrm{g} / \mathrm{kg} /$ day) might have been saturating already (Table II).

NTSD attenuates HF-related pathomorphological changes induced by $\mathrm{CCl}_{4}$. We next investigated the role of NTSD in the pathological morphology changes in liver tissue in HF rats. As shown in Fig. 1 and Table III, most of the normal structure of hepatic lobes in saline treated HF rats (the non-treatment group) was destroyed or disappeared, large amounts of fat tissue degenerated and underwent necrosis, which turned into an empty net with a few liver cells remaining, massive fiber tissue proliferated around the portal and hepatic necrosis area to form a wide, uneven thickness and connected fibrous septa, and the HF scores were $>3$ points, which proved the 



Figure 2. NTSD prevents pathological changes of hepatic fibrosis in $\mathrm{CCl}_{4}$ induced rats. (A) Control; (B) $\mathrm{HF}+\mathrm{saline}$; (C) $\mathrm{HF}+\mathrm{NTSD}$ (28.4 g/kg/day); (D) HF+NTSD (14.2 g/kg/day); (E) HF+NTSD (7.1 g/kg/day); (F) HF+TSP (0.6 g/kg/day).

Table III. The effect of NTSD treatment on HF score in rats.

\begin{tabular}{lcrrrrr}
\hline & & \multicolumn{5}{c}{ HF score } \\
\cline { 3 - 7 } Rats & Treatment (g/kg/day) & 0 & 1 & 2 & 3 & 4 \\
\hline \multirow{2}{*}{ Normal } & Saline & 10 & 0 & 0 & 0 & 0 \\
& Saline & 0 & 0 & 0 & 10 & 5 \\
& NTSD & 0 & 8 & 6 & 1 & 0 \\
& 28.4 & & & & & \\
HF & 14.2 & 0 & 7 & 7 & 1 & 0 \\
& 7.1 & 0 & 8 & 5 & 2 & 0 \\
& TSP 0.6 & 0 & 6 & 7 & 2 & 0 \\
\hline
\end{tabular}

success of the HF model. Compared with the non-treatment HF group, NTSD and TSP treatment groups had less hepatic lobe destruction, reduced fat degeneration, decreased inflammatory cell infiltrations, mild hyperplasia of collagen fiber, only thin fiber bundles, no obvious false lobules, and significantly decreased HF scores (Fig. 2 and Table III). Therefore, the above results clearly illustrated that both NTSD and TSP could improve the pathological changes of liver tissue in $\mathrm{HF}$ rats, and the results were consistent with the improvement of liver function.
NTSD-containing serum inhibits the proliferation of HSC-T6 cells. The activation and proliferation of HSC played a key role in the occurrence and development of $\operatorname{HF}(2,4)$. To investigate the protection mechanism of NTSD in HF rats, we studied the effects of NTSD on the growth of HSC-T6 cells in vitro. After $72 \mathrm{~h}$ of culture in NTSD serum-containing medium, HSC-T6 cells were slightly smaller and rounder, with a reduced adherent ability, and this change was dose-dependent (Fig. 3A). CCK-8 assay showed that NTSD-containing serum inhibited HSC-T6 cell proliferation in a dose-dependent manner and the inhibitory effect of high dose NTSD was more effective than TSP-containing serum (Fig. 3B).

RT-PCR and western blotting was used to test for any PCNA gene expression changes of HSC-T6 after NTSD and TSP-containing serum treatment. The expression level of PCNA is closely related to the synthesis of DNA and an indicator reflecting the state of cell proliferation (16). As shown in Fig. 3C and D, compared with control cells, both high dose NTSD and TSP-containing serum treated cells showed decreased transcription levels of mRNA and PCNA protein expression, with high dose NTSD-containing serum showing the highest effect, which is consistent with the previous cell proliferation data (refer to the references cited).

To analyze further the cell proliferation inhibitory effect of NTSD and TSP, the effects of drugs on the cell cycle of HSC-T6 was analyzed. Compared with control cells, cells treated by NTSD and TSP-containing serum for $72 \mathrm{~h}$ showed an obvious 
A
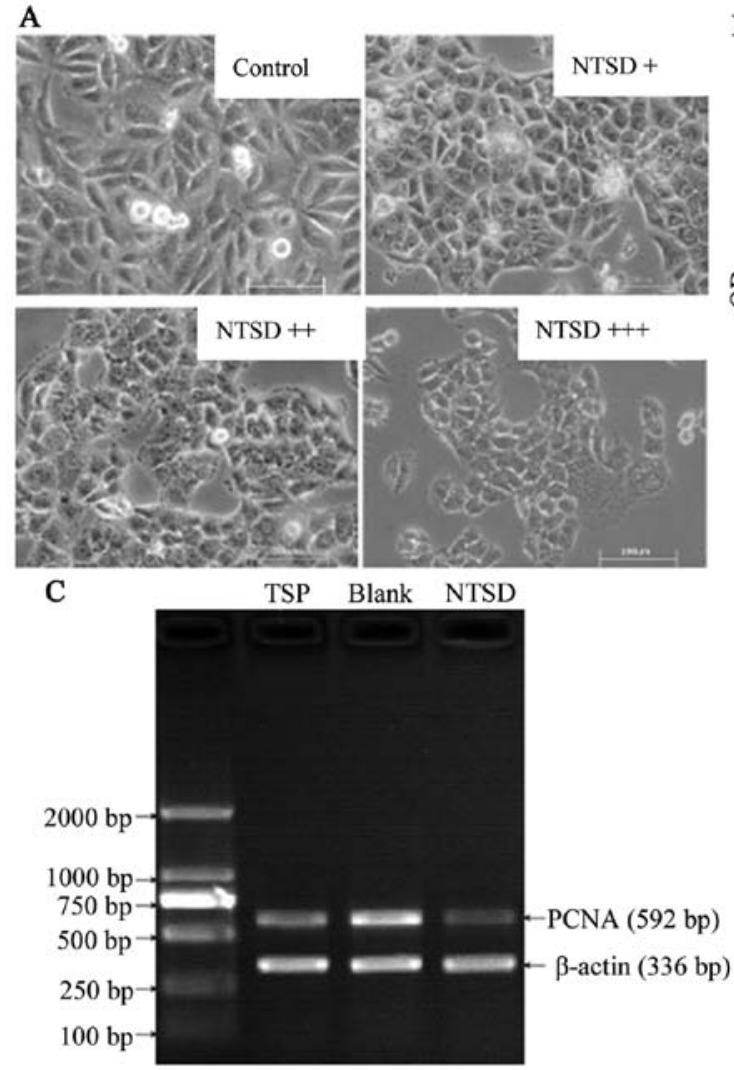

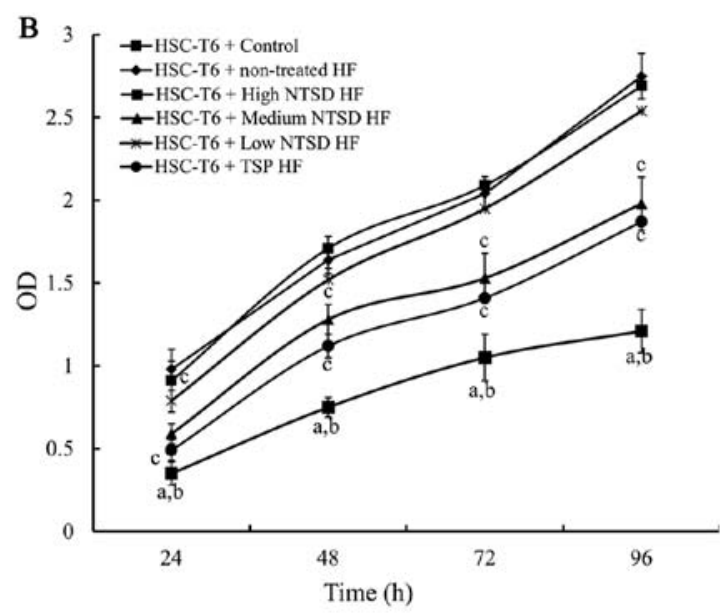

D

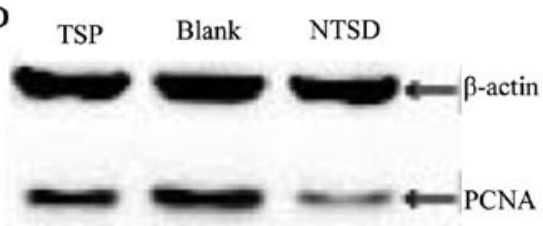

Figure 3. NTSD containing serum inhibited HSC-T6 cell proliferation. We added different doses of NTSD and TSP-containing serum into the HSC-T6 cell culture medium and harvested the cells for analysis after $72 \mathrm{~h}$. (A) Observed HSC-T6 cell morphology changes; (B) cell proliferation curve, detected by the CCK-8 assay, ( $n=3$, data presented as mean \pm SD); (C) PCNA mRNA level tested by RT-PCR; (D) PCNA protein level determined by western blot analysis . For (C) and (D) only a high dose NTSD containing serum $(28.4 \mathrm{~g} / \mathrm{kg} / \mathrm{day})$ was applied.


Figure 4. NTSD-containing serum induced S-phase arrest of HSC-T6 cells Different doses of NTSD and TSP-containing serum was added to the HSC-T6 cell culture medium, the cells collected for PI labeling after $72 \mathrm{~h}$, and cell cycle analyzed using flow cytometry.

S-phase arrest $(\mathrm{P}<0.05)$. As shown in Fig. 4, the proportions of S-phase in control cells, low dose NTSD, medium dose NTSD, high dose NTSD, and TSP-containing serum were 23.26 \pm 3.25 , $25.40 \pm 4.16,32.90 \pm 5.31,42.62 \pm 7.52$ and $30.91 \pm 4.86 \%$, respectively. Therefore, both NTSD and TSP effectively induced S-phase arrest and inhibited the proliferation of HSC-T6 cells in vitro.
NTSD-containing serum promoted HSC-T6 cell apoptosis. We further studied if the NTSD containing serum could promote HSC-T6 cell apoptosis. As shown in Fig. 5, $72 \mathrm{~h}$ after drug containing serum treatment, FCM cell apoptosis detection showed that NTSD could induce HSC-T6 cell apoptosis in a dose-dependent manner, and percentages of apoptotic cells were $2.89 \pm 0.74,5.64 \pm 1.03$ and $8.98 \pm 1.82 \%$, respectively. Similarly, TSP-containing serum also significantly promoted apoptosis of HSC-T6 cells, and the apoptosis percentage was $8.47 \pm 1.69 \%$ (Fig. 5). Hence, these data clearly showed that NTSD had the ability to induce apoptosis of HSC-T6 cells.

NTSD inhibited the TGF- $\beta 1 /$ Smad signaling pathway. The TGF- $\beta 1 /$ Smad signaling pathway is one of the most important signaling pathways that drives the development of $\operatorname{HF}(5,17)$. Therefore, the role of NTSD treatment on the TGF- $\beta 1 / \mathrm{Smad}$ signaling pathway of HF rats was investigated. Liver tissue immunohistochemical results showed that compared with normal rats, the expression of TGF- $\beta 1$ and Smad 3 in the liver of HF rats was significantly increased, while the expression of Smad7 was decreased, which supported a role of the TGF- $\beta 1 /$ Smad signaling pathway in promoting the development of HF (Fig. 6). More importantly, low, medium and high dose NTSD and TSP significantly decreased the TGF- $\beta 1$ and Smad3 expression levels and increased Smad7 (which is an inhibitory Smad protein against Smad3) expression, suggesting that NTSD and TSP could inhibit the TGF- $\beta 1 /$ Smad signaling pathway in multiple ways. In order to confirm further the 

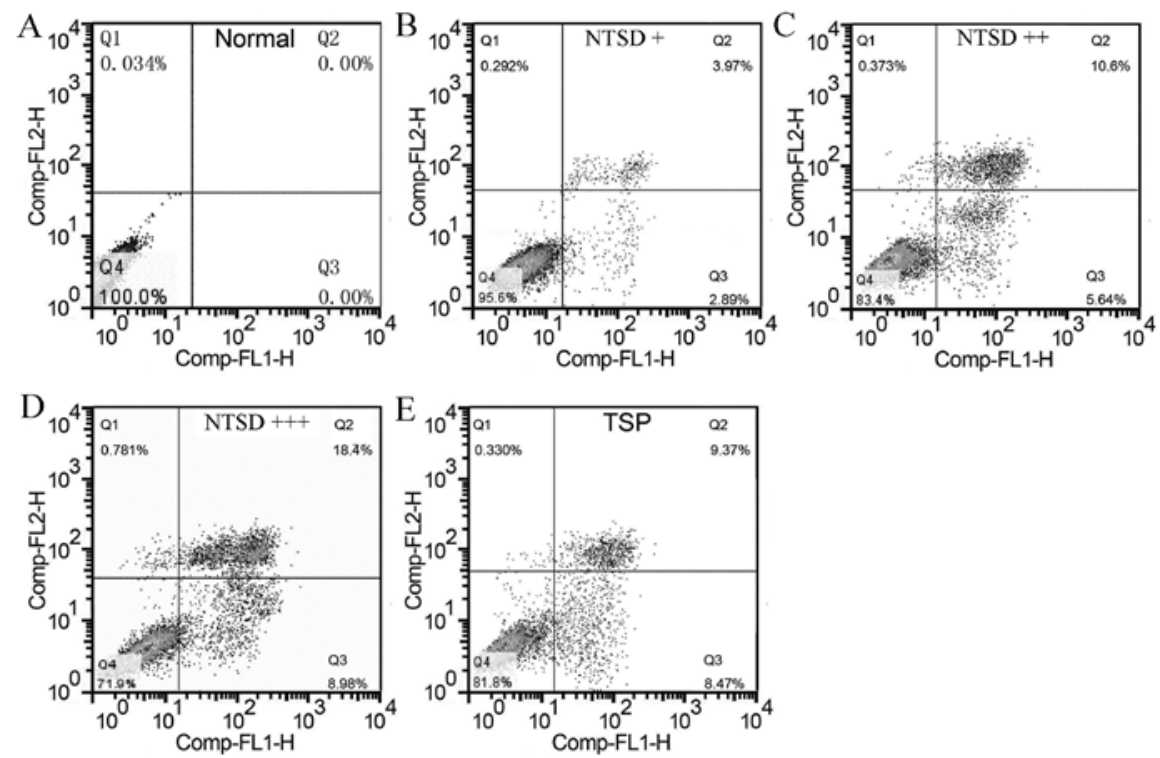

Figure 5. (A-E) NTSD-containing serum promoted HSC-T6 cell apoptosis. Different doses of NTSD and TSP-containing serum were added to the HSC-T6 cell culture medium, and the cells subsequently collected for FCM cell apoptosis analysis after $72 \mathrm{~h}(\mathrm{n}=3)$.
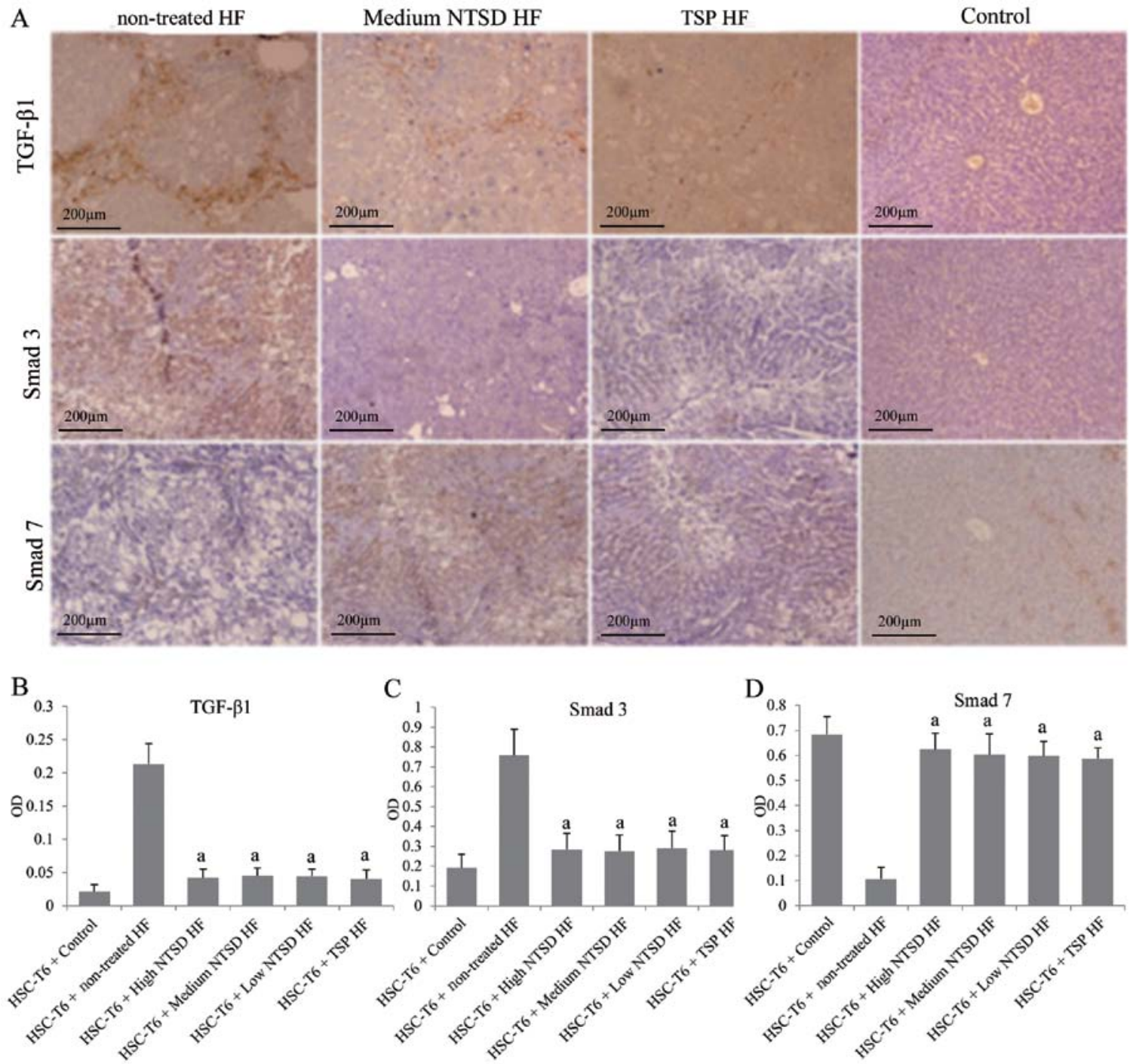

Figure 6. Liver tissue immunohistochemistry results showing that NTSD and TSP treatment significantly decreased the expression of TGF- $\beta 1$ and Smad3 in the liver of HF rats, but the expression level of Smad7 was increased. (A) Representative immunohistochemistry staining images (brown dyes); (B-D) dye quantifications, ${ }^{\mathrm{a}} \mathrm{P}<0.05$ compared to the non-treated HF group. 

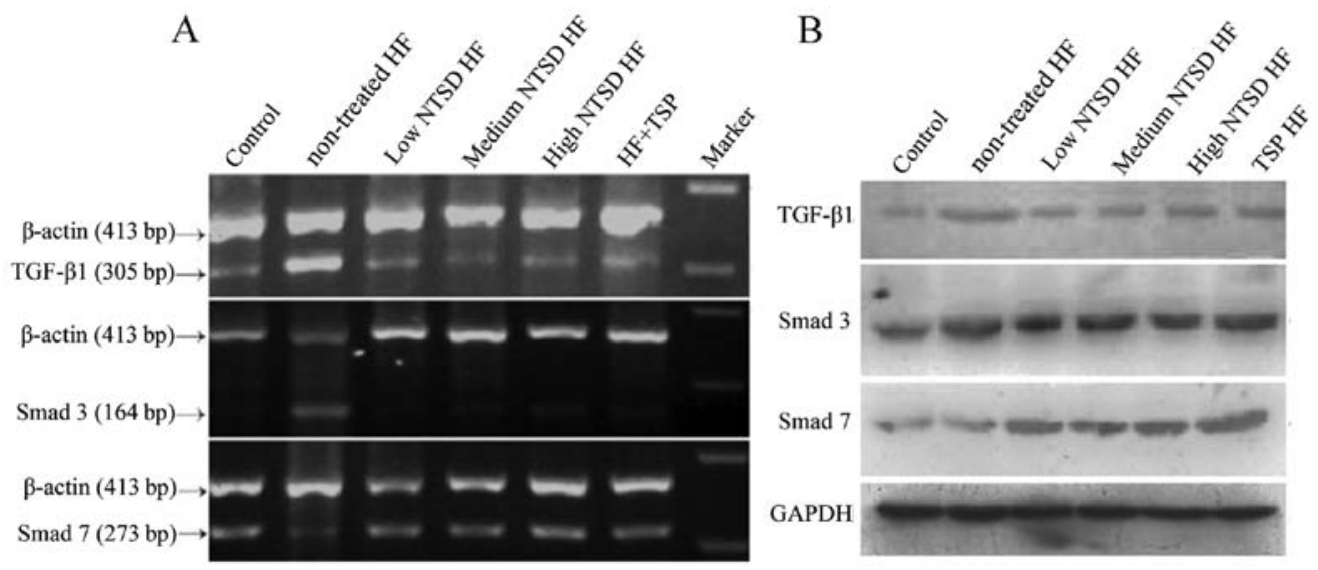

Figure 7. (A) RT-PCR and (B) western blot analysis showing that NTSD and TSP treatment significantly decreased the expression of TGF- $\beta 1$ and Smad 3 in the liver of HF rats, but the expression level of Smad7 was increased.

changes in the expression of TGF- $\beta 1$, Smad3 and Smad7 in the treatment of NTSD and TSP, RT-PCR and western blotting was used. As shown in Fig. 7, at mRNA and protein levels, changes were detected in the expression of TGF- $\beta 1$, Smad3 and Smad7, which were consistent with the immunohistochemical results. Therefore, the discovery that NTSD and TSP could significantly inhibit TGF- $\beta 1 /$ Smad signaling pathway, strongly explains their anti-HF effects.

\section{Discussion}

In the present study, the commonly used (in China) anti-HF drug TSP was modified in order to enhance its availability as well as to reduce the costs for its production and unwanted side-effects. The efficacy of the newly developed NTSD was compared with the conventional TSP medication in a rat HF model and in in vitro experiments. In the NTSD formula, Radix Astragali, Poria and Artemisia capillaris were added. We chose these modifications because Radix Astragali has been shown in previous studies to downregulate TGF- $\beta /$ Smad signaling in rat asthma airway remodeling and HE models $(18,19)$ and also Poria downregulated TGF- $\beta 1$ in a rat pulmonary fibrosis model (20). In addition, Artemisia capillaris flavonoids were shown to have liver protection effects in a $\mathrm{CCl}_{4}$ rat model, which was visible as a reduced serum ALT concentration decrease of $57 \%$ in HF rats (21). Ingredients in both formulas with previously reported effects on TGF- $\beta 1$ downregulation in HF rats and Lx-1 hepatic stellate cells are bupleurum root (22) and turtle shell (23).

In our first experiment, we found that ALT and AST serum concentrations in the non-treatment (saline) HF rats were $\sim 17$ and 12 times enhanced, respectively compared to the healthy controls, which is in agreement with previous literature $(24,25)$. The serum albumin concentrations were reduced, which is also indicative of HF development as described in a previous study (26). Serum globulin concentrations in HF rat sera did not change significantly though the globulin/albumin ratio was lower (1.26 vs. 0.8$)$ in untreated HF than in healthy rats, which is in agreement with a previous study on $\mathrm{CCl}_{4}$-induced $\mathrm{HF}$ in rats (27). Treatment with NTSD could alleviate the HF related ALT increase by 70 and TSP by $77 \%$, and the AST increase was reduced by $61 \%$ by NTSD as well as $53 \%$ by TSP. Also the decrease in serum albumin concentration was significantly lower in all treated HF rats compared to the non-treated HF animals (Table II). After liver injury, HSCs are stimulated by various pathogenic factors from the static to the proliferation state, which promotes a large amount of ECM deposition, leading to liver fibrosis $(28,29)$. Our histopathological findings revealed that pathological liver cell damage was most obviously visible in non-treated MF rats, but was essentially reduced in all treated MF rats (Table III and Fig. 2), reflecting the trend of AST and ALT data. These findings confirmed that NTSD as a treatment for $\mathrm{CCl}_{4}$-induced HF was as efficient as the conventional TPS medication.

The abnormal elevation of TGF- $\beta 1$ expression is associated with the pathogenesis of many liver diseases, such as hepatitis virus infection, and TGF- $\beta 1$ was increased in either the acute or chronic inflammatory microenvironment $(30,31)$. NTSD and TSP significantly decreased Smad 3 expression levels and increased Smad7 expression. Smad3 is an important downstream signaling molecule of TGF- $\beta 1$, which is closely related to the activation of $\operatorname{HSC}(32,33)$, while Smad7 is a major regulatory protein that inhibits $\operatorname{Smad} 3$, and its overexpression can play a protective role in $\operatorname{HF}(8,34)$. Therefore, the hepatoprotective function of NTSD and TSP can at least in part be attributed to the downregulation of TGF- $\beta 1 /$ Smad signaling.

Our cell proliferation assay showed that NTSD slowed down the proliferation of HSC-T6 cells, arrested the cells in the $\mathrm{S}$-phase as well as induced their apoptosis, which might be attributed to reduced TGF- $\beta 1$ expression, since a recent study reported that TGF- $\beta 1$ exposed HSC-T6 cells exhibited increased proliferation and reduced apoptosis due to activation of autophagy (35).

There are some shortcomings in the present study. We currently only studied the influence of NTSD on TGF- $\beta 1$ related signaling, but not on other mechanisms especially cell protection factors in HF (e.g. interferon gamma) and NTSD effects on hepatocytes still needs further research. In addition, potential reduction in the side-effects of NTSD also requires further evaluation.

In conclusion, this study provides an improved anti-HF TCM formula. NTSD could effectively improve the liver function of $\mathrm{CCl}_{4}$-induced $\mathrm{HF}$ in rats and prevent the destruction of hepatic tissue and the progression of fibrosis. We found that 
NTSD promoted HSC apoptosis and inhibited their proliferation and thus proved our hypothesis that NTSD downregulated the expression of TGF- $\beta 1$ and Smad3, as well as increased the expression of Smad7, thus inhibiting the role of TGF- $\beta 1 /$ Smad signaling pathway in promoting the secretion of ECM by activated HSCs.

\section{Acknowledgements}

The present study was supported by the National Natural Science Foundation (81273918), the Project of Traditional Chinese Medicine Science and Technology of Chongqing (2012-2-63) and the Specific Projiect of Traditional Chinese Medicine of Chinese PLA (2010ZYZ231), China.

\section{References}

1. Mortality GBD: Global, regional, and national age-sex specific all-cause and cause-specific mortality for 240 causes of death, 1990-2013: A systematic analysis for the Global Burden of Disease Study 2013. Lancet 385: 117-171, 2015.

2. Henderson NC and Iredale JP: Liver fibrosis: Cellular mechanisms of progression and resolution. Clin Sci (Lond) 112: 265-280, 2007.

3. Parsons CJ, Takashima M and Rippe RA: Molecular mechanisms of hepatic fibrogenesis. J Gastroenterol Hepatol 22 (Suppl 1) S79-S84, 2007.

4. Tsukada S, Parsons CJ and Rippe RA: Mechanisms of liver fibrosis. Clin Chim Acta 364: 33-60, 2006.

5. Cui W, Jin HB and Li ZW: Mechanism of the transforming growth factor-beta induction of fibronectin expression in hepatic stem-like cells. Braz J Med Biol Res 43: 36-42, 2010.

6. Yoshida K, Murata M, Yamaguchi T and Matsuzaki K: TGF- $\beta$ / Smad signaling during hepatic fibro-carcinogenesis (Review). Int J Oncol 45: 1363-1371, 2014

7. Kaimori A, Potter J, Kaimori JY, Wang C, Mezey E and Koteish A: Transforming growth factor-betal induces an epithelial-to-mesenchymal transition state in mouse hepatocytes in vitro. J Biol Chem 282: 22089-22101, 2007.

8. Tahashi Y, Matsuzaki K, Date M, Yoshida K, Furukawa F, Sugano Y, Matsushita M, Himeno Y, Inagaki Y and Inoue K: Differential regulation of TGF-beta signal in hepatic stellate cells between acute and chronic rat liver injury. Hepatology 35: 49-61, 2002.

9. Wells RG: Cellular sources of extracellular matrix in hepatic fibrosis. Clin Liver Dis 12: 759-768, viii, 2008.

10. Zhang Q and Jin S: The modern clinical application and experimental research progress of turtule shell pills. J Hebei Tradit Chin Med Pharmacol 21: 35-36, 2006.

11. Lin W, Wei N, Gao B, Jiang G and Chang Y: Systematic evaluation of therapeutic effect of compound turtule shell pills against hepatic fibrosis. Chin J Gastroenterol Hepatol 16: 69-72, 2007.

12. Gao J, Tao J and Zhao C: The experimental study of turtle shell pills in prevention and treatment of hepatic fibrosis. Chin Arch Tradit Chin Med 11: 2462-2471, 2008.

13. Xi Z, Luan X and Li K: The study of dormant insect on inhibiting immune hepatic fibrosis in rats. Tradit Chin Med Res 17: 38-40, 2001.

14. Xu L and Liu P: The observation of effects on anti-hepatic fibrosis of peach extract-the study of immunohistochemistry and collagen metabollism. Tradit Chin Med Res 5: 14-16, 1993.

15. Lu Y, Ren X and Chen Y: Dynamic observation of the effects of turtle shell pills on liver collgen and serum pre-collagen III during the hepatic fibrosis process in rats. Henan Tradit Chin Med 21: 19, 2001.
16. Moldovan GL, Pfander B and Jentsch S: PCNA, the maestro of the replication fork. Cell 129: 665-679, 2007.

17. Gressner AM, Weiskirchen R, Breitkopf K and Dooley S: Roles of TGF-beta in hepatic fibrosis. Front Biosci 7: d793-d807, 2002.

18. Dai H, Zhang WX, He XL, Zhao RX, Fang L and Li CC: Effect of TGF-B1/Smad3 aignal pathway on airway remodelling in asthma rats with the regulation of Radix Astragali. Chin Arch Tradit Chin Med 28: 2494-2498, 2010.

19. Huang J, Zhang C, Zhan F and Zhang J: Effects of astragalan on liver fibrosis rat in TGF- $\beta 1 /$ Smads signal pathway. China J Tradit Chin Med Pharm 30: 2184-2186, 2015.

20. Jiang W, Zhou ZS, Hu HB and Liu BJ: The Effect of Fuling, Yiyiren and Dongguazi on serum TGF- $\beta 1$ and TNF- $\alpha$ levels in rats with pulmonary fibrosis. Med J Qilu 28: 237-240, 2013.

21. Niu SL, Wu ZL and Yao JJ: Hepatoprotective effect of Artemisia capillaris thumb flavones extract on chronic liver in-jury induced by carbon tetrachloride in rats. Med J Chin People's Armed Police Forces 26: 162-166, 2015.

22. Shang LZ, Wang F, Wang Q, et al: Effects and mechanism of chaihu shugan powder on TGF- $\beta 1 /$ Smad signaling pathways in hepatic fibrosis model rats. Chin J Exp Tradit Med Formulae 21: 125-128, 2015.

23. Gao JR, Yao HP, Liu YW, et al: Turtle carapace decoction and drug containing serum on hepatic stellate cells. Chin Arch Tradit Chin Med 31: 2524-2528, 2013.

24. Zechini B, Pasquazzi C and Aceti A: Correlation of serum aminotransferases with HCV RNA levels and histological findings in patients with chronic hepatitis $\mathrm{C}$ : The role of serum aspartate transaminase in the evaluation of disease progression. Eur J Gastroenterol Hepatol 16: 891-896, 2004.

25. Pradat P, Alberti A, Poynard T, Esteban JI, Weiland O, Marcellin P, Badalamenti $S$ and Trépo C: Predictive value of ALT levels for histologic findings in chronic hepatitis C: A European collaborative study. Hepatology 36: 973-977, 2002.

26. Natsume M, Tsuji H, Harada A, Akiyama M, Yano T, Ishikura $H$, Nakanishi I, Matsushima K, Kaneko S and Mukaida N: Attenuated liver fibrosis and depressed serum albumin levels in carbon tetrachloride-treated IL-6-deficient mice. J Leukoc Biol 66: 601-608, 1999.

27. Hassan EM, El-Kherbawy GM, Ali MAM and Dewidar OM: The potential effect of special formulas on cirrhotic rats. Food Nutr Sci 4: 594-603, 2013.

28. Soon RK Jr and Yee HF Jr: Stellate cell contraction: Role, regulation, and potential therapeutic target. Clin Liver Dis 12: 791-803, viii, 2008.

29. Marra F: Hepatic stellate cells and the regulation of liver inflammation. J Hepatol 31: 1120-1130, 1999.

30. Kanzler S, Baumann M, Schirmacher P, Dries V, Bayer E, Gerken G, Dienes HP and Lohse AW: Prediction of progressive liver fibrosis in hepatitis $\mathrm{C}$ infection by serum and tissue levels of transforming growth factor-beta. J Viral Hepat 8: 430-437, 2001.

31. Date M, Matsuzaki K, Matsushita M, Tahashi Y, Furukawa F and Inoue K: Modulation of transforming growth factor beta function in hepatocytes and hepatic stellate cells in rat liver injury. Gut 46: 719-724, 2000

32. Flanders KC: Smad 3 as a mediator of the fibrotic response. Int $J$ Exp Pathol 85: 47-64, 2004.

33. Latella G, Vetuschi A, Sferra R, Catitti V, D'Angelo A, Zanninelli G, Flanders KC and Gaudio E: Targeted disruption of Smad3 confers resistance to the development of dimethylnitrosamine-induced hepatic fibrosis in mice. Liver Int 29: 997-1009, 2009.

34. Dooley S, Hamzavi J, Breitkopf K, Wiercinska E, Said HM, Lorenzen J, Ten Dijke P and Gressner AM: Smad7 prevents activation of hepatic stellate cells and liver fibrosis in rats. Gastroenterology 125: 178-191, 2003.

35. Fu MY, He YJ, Lv X, Liu ZH, Shen Y, Ye GR, Deng YM and Shu JC: Transforming growth factor- $\beta 1$ reduces apoptosis via autophagy activation in hepatic stellate cells. Mol Med Rep 10: 1282-1288, 2014 